\title{
Temporo-spatial Variations in Resistance Determinants and Clonality of Acinetobacter Baumannii and Pseudomonas Aeruginosa Strains From Romanian Hospitals and Wastewaters
}

\section{Irina Gheorghe}

Department of Microbiology and Immunology, Faculty of Biology, University of Bucharest

Ilda Czobor Barbu ( $\square$ ilda.barbu@bio.unibuc.ro)

Department of Microbiology and Immunology, Faculty of Biology, University of Bucharest

\section{Laura loana Popa}

Research Institute of the University of Bucharest (ICUB), Bucharest

\section{Gratiela Gradisteanu Parcalabioru}

Research Institute of the University of Bucharest (ICUB), Bucharest

Marcela Popa

Research Institute of the University of Bucharest (ICUB), Bucharest

\section{Luminita Marutescu}

Department of Microbiology and Immunology, Faculty of Biology, University of Bucharest

Mihai Nita-Lazar

National Institute for Research and Development for Industrial Ecology

Alina Banciu

National Institute for Research and Development for Industrial Ecology

\section{Catalina Stoica}

National Institute for Research and Development for Industrial Ecology

\section{Stefania Gheorghe}

National Institute for Research and Development for Industrial Ecology

Irina Lucaciu

National Institute for Research and Development for Industrial Ecology

\section{Oana Sandulescu}

National Institute for Infectious Diseases 'Matei Bals', Bucharest

Simona Paraschiv

National Institute for Infectious Diseases 'Matei Bals', Bucharest

\section{Marius Surleac}

National Institute for Infectious Diseases 'Matei Bals', Bucharest

\section{Daniela Talapan}

National Institute for Infectious Diseases 'Matei Bals', Bucharest

\section{Andrei Alexandru Muntean}

"Cantacuzino" National Medical-Military Research and Development Institute, Bucharest 


\section{Madalina Preda}

"Cantacuzino" National Medical-Military Research and Development Institute, Bucharest Madalina-Maria Muntean

"Cantacuzino" National Medical-Military Research and Development Institute, Bucharest Cristiana Cerasella Dragomirescu

"Cantacuzino" National Medical-Military Research and Development Institute, Bucharest

\section{Mircea loan Popa}

"Cantacuzino" National Medical-Military Research and Development Institute, Bucharest

\section{Dan Otelea}

National Institute for Infectious Diseases 'Matei Bals', Bucharest

\section{Mariana Carmen Chifiriuc}

Department of Microbiology and Immunology, Faculty of Biology, University of Bucharest

\section{Research Article}

Keywords: Antimicrobial Resistance, Nonfermenting Gram-Negative Bacilli, Nosocomial Infections, Wastewater, Epidemic clones

Posted Date: February 4th, 2022

DOI: https://doi.org/10.21203/rs.3.rs-1294567/v1

License: (a) This work is licensed under a Creative Commons Attribution 4.0 International License. Read Full License 


\section{Abstract}

Background: Romania is one of the European countries reporting very high antimicrobial resistance (AMR) rates and consumption of antimicrobials. We aimed to characterize the AMR profiles and clonality of 304 multi-drug resistant (MDR), carbapenemase (CP) and extended spectrum beta-lactamase (ESBL) producing Acinetobacter baumannii $(A b)$ and Pseudomonas aeruginosa $(P a)$ strains isolated during two consecutive years (2018 and 2019) from hospital settings, hospital collecting sewage tanks and the receiving wastewater treatment plants (WWTPs) located in the main geographical regions of Romania.

Methods: The strains were isolated on chromogenic media and identified by MALDI-TOF-MS. Antibiotic susceptibility testing and confirmation of ESBL- and CP-producing phenotype were performed. The genetic analyses consisted of PCR for ESBL and CP genes, horizontal gene transfer experiments, whole-genome sequencing (WGS), assembling, annotation and characterization.

Results: Both clinical and aquatic isolates exhibited high MDR rates, especially the $A b$ strains isolated from nosocomial infections and hospital effluents. The phenotypic resistance profiles and MDR rates have largely varied by sampling point and by geographic location. The highest MDR rates in aquatic isolates were recorded in Galați WWTP followed by Bucharest. The $A b$ strains harbored mostly bla $a_{\mathrm{OXA}-23}, b / a_{\mathrm{OXA}-24}, b / a_{\mathrm{SHV}}, b / a_{\mathrm{TEM}}$ and $b / a_{\mathrm{GES}}$, while $P a$ strains $b / a_{\mathrm{IMP}}, b / a_{\mathrm{VIM}}, b / a_{\mathrm{NDM}}, b / a_{\mathrm{VEB}}, b / a_{\mathrm{GES}}$ and $b / a_{\mathrm{TEM}}$, with high variations depending on the geographical zone and the sampling point. The WGS analysis revealed the presence of antibiotic resistance genes (ARGs) to other antibiotic classes, such as aminoglycosides, tetracyclines, sulphonamides, fosfomycin, phenicols, trimethoprim-sulfamethoxazole as well as class 1 integrons. The molecular $A b$ and $P a$ analyses highlighted: i) the presence of epidemic clones such as ST2 for $A b$ and ST233 and ST357 for $P a$; ii) the relatedness between clinical and hospital wastewater strains and iii) the possible dissemination of clinical $A b$ strains belonging to ST2 (also proved in the conjugation assays to transfer bla $a_{\text {OXA-23 }}$ or bla OXA-72 genes), ST79 and ST492 and of clinical Pa strains belonging to ST357, ST640 and ST621 in the wastewaters.

Conclusion: The prevalent clones were strongly associated with the presence of class 1 integrons, suggesting that those isolates could be a significant reservoir of ARGs and are able to persist into the environment.

\section{Introduction}

Antimicrobial resistance (AMR) is an increasing worldwide concern. Romania is one of the European countries reporting elevated AMR rates and the country with the third highest consumption of antibacterials for systemic use in the community sector (according to data from in 2020) [1]. Antibiotics are one of the most popular pharmaceuticals used in human medicine, veterinary care, and farming [2-4]. Unfortunately, they are also frequent contaminants in domestic wastewater, municipal sewage and wastewater treatment plant (WWTP) effluents from where they dissipate into the environment [5-7]. Hospitals generate huge amounts of wastewater per day, high in pathogenic microorganisms, antibiotics and other pharmaceutical or toxic substances, which transform WWTPs in one of the key sources of both antibiotic resistant bacteria (ARB) and antibiotic resistant genes (ARGs). ARGs are disseminated via mobile genetic elements (MGEs) to other non-resistant bacterial strains [8-10] during the wastewater treatment steps. The WWTPs standard procedures only partially remove ARGs, ARBs and other resilient pollutants. The remaining contaminants are contributing to the pollution of the natural environments, facilitating the selection and dissemination of ARGs and ARB [7, 11-13] into crops, 
animals and humans, from which they could be (re)introduced into the medical environment [14]. Also, the ARGs can be transmitted to the aquatic microbiota via horizontal gene transfer (HGT), which is increased in bacterial biofilms formed in natural environments and under stress caused by various pharmaceutical and heavy metal contamination [15].

The lack of surveillance of non-clinical reservoirs is considered one of the main contributors to the spread of AMR, particularly in developing countries. In this context, during the last years, international authorities have made considerable efforts to improve the monitoring of AMR in different environments, underlining the necessity to strengthen the intersectoral human, animal and agricultural cooperation. One of the priority topics of The Joint Programme Initiative on Antimicrobial Resistance (JPIAMR) is represented by the elucidation of the role of the environment as a source for the selection and dissemination of AMR. One important goal is mapping the distribution of multidrug-resistant (MDR) pathogens and plasmids of different genomic lineages in different clinical and aquatic compartments. This important insight could be translated into policy measures to monitor AMR and control the emergence and spread of ARB $[16,17]$.

Acinetobacter baumannii $(A b)$ and Pseudomonas aeruginosa $(P a)$ are members of the initially designed "ESKAPE", then "ESCAPE" (Enterococcus faecium, Staphylococcus aureus, Clostridioides difficile, Acinetobacter baumannii, Pseudomonas aeruginosa, and Enterobacteriaceae) group [18, 19]. Centers for Disease Control and Prevention (CDC) classified them as hazard urgent level due to their often MDR features [20] and therefore requiring concerted research and management efforts [21]. $A b$ and $P a$ are exhibiting all known AMR mechanisms, such as drug inactivation/alteration, modification of drug binding sites/targets, cell permeability modification and biofilm development [22]. One of the most clinically relevant mechanisms of resistance in $A b$ and $\mathrm{Pa}$ strains is represented by the production of antibiotic inactivating hydrolytic enzymes, especially carbapenemases (CPs) and extended-spectrum $\beta$-lactamases (ESBLs).

So far, five main groups of acquired chromosomal or plasmid located class $D$-lactamases (CHDLs) with different geographic distribution have been identified in $A b$ strains, i.e. OXA-23, OXA-24/-40, OXA-58, OXA-143 and OXA-235 [23]. In Pa strains, there were identified eleven families of class $B$ or of metallo- $\beta$-lactamases (MBL) [Verona integron-encoded MBL (VIM); imipenemases (IMPs); New Delhi Metallo- $\beta$-lactamase (NDM); Australian imipenemase (AIM); Central Alberta MBL (CAM); Dutch imipenemase (DIM); Florence imipenemase (FIM); German imipenemase (GIM); Hamburg MBL (HMB); São Paulo MBL (SPM) and Seoul imipenemase (SIM)], chromosomal/plasmid encoded or integron-borne, the VIM, IMP and NDM types being distributed worldwide [24].

Presently, there are insufficient data on the $A b$ and Pa release from hospital settings and survival into the wastewater and eventually into the natural recipient. Despite the huge burden of AMR presence in Romania and its significant overall impact on European AMR rates, the genetic relationships between the bacterial strains isolated from different aquatic environmental and clinical compartments were not investigated at national level.

Our aim was to perform a phenotypic and molecular characterization of the acquired resistome of a significant number of MDR, $\mathrm{CP}$ and ESBL producing $A b$ and $P a$ strains isolated in the same temporal sequence from the hospital environments and the receiving wastewater network from different counties in Romania.

\section{Methods}




\section{Phenotypic characterization of the $A b$ and $P a$ strains}

\section{Sampling location}

The water samples collection took place from September 2018 to August 2019. The collection points were represented by sewage tanks from eight hospital units and their wastewater collecting WWTPs. The eight sampling locations covered several Romanian regions such as the Southern region, with sampling locations in Bucharest (C/H - Glina municipal WWTP 2018/2019), WWTP Târgoviște (E) and WWTP Râmnicu-Vâlcea (J); Central and Western regions: WWTP Cluj (I) and WWTP Timișoara (F); Northern and Eastern regions: WWTP Iași (G) and WWTP Galați (D) (Fig. 1).

The different sampling points from the selected locations were: hospital/WWTP effluent (EF), WWTPs influent (IN), activated sludge (AS) and returned sludge (RS), where all isolated strains were considered within a single group.

\section{Isolation and characterization of $A b$ and $P a$ strains}

The water samples were collected in sterile glass sample containers, transported to the laboratory at $5 \pm 3{ }^{\circ} \mathrm{C}$ and processed within the first $24 \mathrm{~h}$. The water samples were diluted and filtered through $0.45 \mu \mathrm{m}$ pore size membrane filters (Millipore, France), as described in SR EN ISO 9308-2/2014 (for coliform bacteria) and then cultivated on ChromID ESBL agar and ChromID CARBA agar (BioMérieux, France). The resistant colonies obtained after cultivation at $37^{\circ} \mathrm{C}$ for 24 hours in aerobic conditions were subsequently inoculated on the corresponding antibiotic-enriched media for the confirmation of ESBL- or CP-producing phenotype. All resistant strains were identified by MALDI-TOF-MS (Bruker system). In the same time frame with the collection of the water samples (i.e., during a ten-day period prior to the water sampling), clinical strains were isolated belonging to $A b$ and $\mathrm{Pa}$ from intra-hospital infections that occurred in the units discharging the wastewater in the sampled WWTPS.

The antibiotic susceptibility profiles of the identified strains (220 $\mathrm{Ab}$ and $84 \mathrm{~Pa}$ ) were determined using the standard disc diffusion method according to Clinical and Laboratory Standards Institute (CLSI guidelines) for 2018 and $2019[25,26]$.

\section{PCR for ESBL and CP genes}

The $A b$ and Pa strains were screened for CP genes (b/a $a_{\mathrm{VIM}}, b / a_{\mathrm{IMP}}, b / a_{\mathrm{NDM}}, b / a_{\mathrm{KPC}}$ for Pa and bla $a_{0 X \mathrm{~A}-51 / 69-\mathrm{like}}$

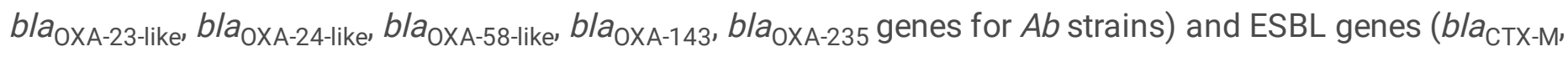
$\left.b / a_{\mathrm{TEM}}, b / a_{\mathrm{SHV}}, b / a_{\mathrm{PER}}, b / a_{\mathrm{VEB}}, b / a_{\mathrm{GES}}\right)$ using previously described primers and PCR protocols $[27,28]$.

\section{Mating experiments}

Transferability of bla $a_{\mathrm{OXA}-23}$ and bla $\mathrm{OXA}_{24}$ genes by conjugation was tested in solid mating using a rifampicin (RIF) resistant Acinetobacter baylyi ADP1 as recipient. Briefly, equal amounts $(100 \mu \mathrm{L})$ of overnight cultures of the donors ( $\mathrm{n}=40 \mathrm{Ab}$ strains from all isolation sampling points) and recipient strains were mixed and incubated in Brain heart infusion agar plates, cells were resuspended in saline solution and selected in plates containing RIF (300 mg/L) and meropenem (MEM) $(0.5 \mathrm{mg} / \mathrm{L})$ [29]. Characterization of the transconjugants were conducted by PCR. 


\section{Whole-genome sequencing (WGS), assembling, annotation and characterization}

To determine the genetic relationships between the clinical and wastewater isolates, 54 strains $(A b, \mathrm{n}=34$ and $P a, \mathrm{n}=20$ ) were selected for WGS, with both clinical and water isolates available for the same geographical location. Total DNA was isolated using DNeasy UltraClean Microbial Kit Qiagen and subjected to Illumina (Nextera DNA Flex Library Prep Kit) sequencing on MiSeq platform. Raw reads were checked for quality using FastQC [30], assembled using Shovill pipeline [31] and primarily annotated using Prokka [32], while the prediction of resistance profiles was performed by using ABRicate [33], ResFinder, PlasmidFinder [34-37], PathogenFinder [38], CARD [39]. Strain relatedness was investigated using MultiLocus Sequence Typing (MLST) [35, 40] and Single Nucleotide Polymorphism (SNP) [41]. Comparative gene analyses were performed using Roary [42] and the output was used to infer phylogenies using RAxML (Maximum Likelihood inference using bootstrap value $\mathrm{N}$ $=1000)$ [43] and visualized using iTOL [44].

\section{Results}

\section{Identification and antibiotic susceptibility profiles of $A b$ and $P a$ strains}

A total number of $220 A b$ and $84 P a$ were isolated from clinical and water samples during the two consecutive years.

Two pilot sampling campaigns were performed, in Bucharest in 2018 from which $66 \mathrm{Ab}$ and $50 \mathrm{~Pa}$ strains were isolated (Table 1).

In 2019, the sampling campaign was extended including, in addition to Bucharest, six other cities that are representative for the main country regions, i.e., North-East (lași, Galați), Central-West (Cluj, Timișoara) and South (Târgoviște, Râmnicu Vâlcea). A total of $154 A b$ and 34 Pa resistant isolates were recovered (see Table 1).

Within the same time frame, clinical $A b$ and $P a$ clinical strains were isolated in hospital units from which wastewater samples were collected. The hospital wastewater was collected and treated by the corresponding WWTPs from the same town.

Table 1. The distribution of $A b$ and $P a$ strains selected for this study. 


\begin{tabular}{|c|c|c|c|c|}
\hline \multirow[t]{2}{*}{ Year } & \multirow[t]{2}{*}{$\begin{array}{c}\text { Romanian } \\
\text { region }\end{array}$} & \multirow[t]{2}{*}{ Isolation source } & \multicolumn{2}{|c|}{$\begin{array}{l}\text { Number (n) of } \\
\text { isolated species }\end{array}$} \\
\hline & & & $A b$ & $P a$ \\
\hline \multirow[t]{6}{*}{2018} & \multirow[t]{6}{*}{ South } & $\begin{array}{c}\text { Bucharest hospital } 1 \text { (Clinical Institute Fundeni-CIF + Institute for } \\
\text { Cardiovascular Emergencies Prof. C.C. Iliescu- IBC CCI) }\end{array}$ & $\mathrm{n}=10$ & $\mathrm{n}=15$ \\
\hline & & Bucharest hospital (H) 1 EF & - & $\mathrm{n}=11$ \\
\hline & & Bucharest hospital (H) 2 (NIIDMB) & $\mathrm{n}=4$ & $\mathrm{n}=3$ \\
\hline & & Bucharest hospital $2 \mathrm{EF}$ & $\mathrm{n}=49$ & $\mathrm{n}=21$ \\
\hline & & Bucharest WWTP C EF & $\mathrm{n}=3$ & - \\
\hline & & Total 2018 & $\mathrm{n}=66$ & $\mathrm{n}=50$ \\
\hline \multirow[t]{20}{*}{2019} & \multirow[t]{9}{*}{ South } & Bucharest hospital 2 & $\mathrm{n}=5$ & - \\
\hline & & Bucharest hospital $2 \mathrm{EF}$ & $\mathrm{n}=21$ & - \\
\hline & & Bucharest WWTP - H & $\mathrm{n}=8$ & - \\
\hline & & Târgoviște hospital & $\mathrm{n}=2$ & $\mathrm{n}=1$ \\
\hline & & Târgoviște hospital EF & $\mathrm{n}=5$ & - \\
\hline & & Targoviște WWTP - E & $\mathrm{n}=30$ & - \\
\hline & & Vâlcea hospital & $\mathrm{n}=2$ & $\mathrm{n}=1$ \\
\hline & & Vâlcea hospital EF & - & $\mathrm{n}=5$ \\
\hline & & Valcea WWTP - J & $\mathrm{n}=10$ & - \\
\hline & \multirow{5}{*}{$\begin{array}{l}\text { Central- } \\
\text { West }\end{array}$} & Cluj hospital & $\mathrm{n}=2$ & $\mathrm{n}=2$ \\
\hline & & Cluj hospital EF & - & $\mathrm{n}=3$ \\
\hline & & Cluj WWTP - I & $\mathrm{n}=5$ & $\mathrm{n}=2$ \\
\hline & & Timișoara hospital & - & $\mathrm{n}=2$ \\
\hline & & Timișoara WWTP - F & $\mathrm{n}=6$ & $\mathrm{n}=2$ \\
\hline & \multirow{6}{*}{$\begin{array}{l}\text { North- } \\
\text { East }\end{array}$} & Iași hospital & $\mathrm{n}=1$ & - \\
\hline & & Iași hospital EF & $\mathrm{n}=1$ & $\mathrm{n}=8$ \\
\hline & & Iași WWTP - G & $\mathrm{n}=15$ & $\mathrm{n}=2$ \\
\hline & & Galați hospital & - & $\mathrm{n}=4$ \\
\hline & & Galați WWTP - D & $\mathrm{n}=41$ & $\mathrm{n}=2$ \\
\hline & & Total 2019 & $\mathrm{n}=154$ & $\mathrm{n}=34$ \\
\hline
\end{tabular}

The analysis of MDR rates from the hospital to the collecting WWTP in the first sampling campaign from 2018 has revealed the following aspects: 1) clinical isolates - all $A b$ and the majority of Pa strains (93.3-100\%) were MDR (Supplemental Tables 2 and 3); 2) hospital EF - all Ab isolates were MDR (Supplemental Table 2), while the Pa strains exhibited various MDR rates (from 25\% to 100\%) (Supplemental Table 3); 3 ) WWTP C, collecting the two hospital EFs - all Ab isolates were MDR (Supplemental Table 2).

In 2019, the MDR rates from hospital to the collecting WWTP were as follows: 1) clinical isolates - with one exception, all $A b$ isolates were MDR (Supplemental Table 2), while the $P a$ strains have shown a high variation of MDR rate (from 0 to $100 \%$ ) with the geographical location (Supplemental Table 3); 2) hospital EF- all $A b$ isolates were MDR (Supplemental Table 2), while the Pa strains exhibited various MDR rates (from 0\% to 100\%) (Supplemental Table 3); 3) WWTPs, collecting the sewages of the sampled hospital units effluents - the MDR resistance rates varied from 0 to $100 \%$ for both $A b$ and $P a$ strains.

Table 2 and 3. AR profiles in clinical and wastewater $A b$ and $P a$ strains.

\section{CP and ESBL encoding genes in clinical and environmental $A b$ and $P a$ strains}

\section{a. Profiles of CP and ESBL genes from the clinical to the aquatic environment in 2018 versus 2019}


The $A b$ strains from the clinical settings to the WWTP effluent and receiving river exhibited different profiles of $\mathrm{CP}$ and ESBLs in the two consecutive years, i.e.: 1) clinical strains - $A b$ strains recovered in 2018 were OXA-23 and OXA-24 producers $\left(64.28 / 42.85 \%\right.$ ) and only $7.14 \%$ were positive for $b / a_{\text {TEM}}$, while in $2019,41.66 \%$ of all intra-hospital $A b$ strains were OXA-23 and OXA-24 producers, $25 \%$ were positive for $b / a_{\mathrm{SHV}}, 16.66 \%$ for $b / a_{\mathrm{VIM}}$ and

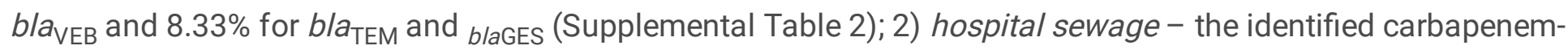
hydrolyzing class $\mathrm{D} \beta$-lactamases (CHLDs) were represented in the two consecutive years by OXA-23 (67.34/96.29\%) and OXA-24 (2.04/0\%), MBLs by VIM (4.08/14.81\%) and ESBLs by TEM (20.41/0\%), SHV and PER (each one 0/3.70\%), GES (0/18.51\%) (Supplemental Table 2); 3) WWTPS - some of the enzymes were common for the strains isolated in 2018 and 2019 [i.e. OXA-24 (57.14/10.25\%); OXA-23 (42.85/53.84\%); TEM (28.57/10.89\%); SHV (14.28/0.64\%)], while some other were different [i.e. NDM in Ab strains from 2018 (14.28\%) and GES (19.87\%); VEB (8.97\%); CTX-M (2.56\%) and PER (0.64\%) in 2019].

The $\mathrm{CP}$ and ESBL genes identified in the Pa isolates during the transmission chain from the clinical sector to the WWTP effluent and receiving river in the two consecutive years were the following: 1) clinical strains - the Pa strains were positive for bla $a_{\mathrm{IMP}}(66.66 / 0 \%)$, bla $\mathrm{VIIM}_{\mathrm{V}}(33.33 / 20 \%)$ and bla $\mathrm{VEB}_{\mathrm{VEB}}(38.88 / 30 \%)$; 2$)$ hospital sewage in the two consecutive years the following MBLs were identified in the Pa strains: VIM (9.37/18.75\%); IMP (9.37/0\%); NDM (0/12.5\%); while the ESBLs were represented by GES (6.25/6.25\%); VEB (43.75/12.5\%) and TEM $(0 / 31.25 \%)$; 3) WWTPs - only the Pa strains isolated in 2019 were positive for ESBL encoding genes [b/a ${ }_{\text {TEM }}$ $(16.66 \%) ; b / a_{\mathrm{GES}}$ and $b / a_{\mathrm{VEB}}(8.33 \%$ each)] (Supplemental Table 3$)$.

\section{b. Geographic distribution of $\mathrm{CP}$ and ESBL genes in clinical and water $A b$ and $P a$ isolates}

The 2018 pilot study was limited to the Bucharest region, and then it was extended during 2019 to other regions of the country, allowing us to perform a comparative analysis regarding the geographic distribution of the $\mathrm{CP}$ and ESBL encoding genes in the $A b$ and $P a$ strains.

Regarding the $A b$ strains, the Southern region shows the largest spectrum and positivity of CP and ESBL encoding genes, both in clinical [i.e., bla $a_{\text {OXA-23 }}(44.44 \%) ; b / a_{\text {OXA-24 }}$ (33.33); bla $a_{V I M}(22.22 \%) ; b l a_{\text {TEM }}$ and bla $a_{\text {SHV }}$ $(11.11 \%)$ ] and the aquatic isolates [hospital sewage: bla $a_{\text {OXA-23 }}(100 \%) ; b / a_{\mathrm{GES}}(19.23 \%) ; b / a_{\mathrm{VIM}}(15.38 \%) ; b / a_{\mathrm{VEB}}$ and $b / a_{\mathrm{SHV}}(3.84 \%)$ and WWTPS: i.e. bla $/ a_{\mathrm{OXA}-23}(44.44 \%) ; b / a_{\mathrm{GES}}(32.09 \%) ; b / a_{\mathrm{TEM}}(18.51 \%) ; b / a_{0 X \mathrm{XA}-24}(14.81 \%) ;$ $b / a_{\text {VEB }}(13.58 \%) ; b / a_{\text {CTX-M }}(4.93 \%)$ and $\left.b / a_{\text {SHV }}(1.23 \%)\right]$.

Central-Western region revealed the presence of the following CP and ESBL encoding genes: 1) in clinical settings all $A b$ strains were $b / a_{\mathrm{VEB}}$ positive; $50 \%$ were $b / a_{\mathrm{OXA}-23}$ and $b / a_{\mathrm{OXA}-24}$ positive; 2 ) the aquatic isolates recovered from the two sampled WWTPs were bla $a_{\text {XXA-23 }}$ and bla $a_{\text {VEB }}$ positive (23.07\% each of them).

In the North-Eastern region the CP and ESBL identified in $A b$ strains from the hospitals to the WWTP were the following: 1) all clinical $A b$ strains were OXA-24 producers; while in the sampled WWTPs the $A b$ strains harbored OXA-23 (72.58\%); OXA-24 (6.45\%); TEM (3.22\%) and PER (1.61\%) (Fig. 2).

The geographical distribution of the CP/ESBLs found in Pa strains isolated from intra-hospital infections, the hospital sewage tank and the sampled WWTP from the corresponding city: in the Southern region $50 \%$ of nosocomial Pa strains were VEB producers, while the wastewater Pa strains harbored bla $a_{\text {VEB }}(40 \%)$, blaNDM $(40 \%)$ and $b / a_{\mathrm{GES}}(20 \%)$; in the North-Eastern region, $50 \%$ of clinical Pa strains were VEB producers; $62.5 \%$ of the 
hospital sewages strains were positive for b/a $a_{\mathrm{TEM}} ; 50 \%$ respectively $25 \%$ of the WWTPs were $b / a_{\mathrm{VEB}}$ and $b / a_{\mathrm{TEM}}$ positive. The $P a$ strains from the Central-Western regions revealed different CP/ESBLs in clinical/hospital sewage (VIM) and in the sampled WWTPs (14.28\% were GES positive) (Fig.3).

\section{c. WGS analysis of clinical and wastewater $A b$ and $P a$ isolates}

\section{Acquired resistome}

The WGS analysis allowed detailed insights in the acquired resistome of the selected strains.

In case of nine $A b$ strains recovered in 2018 in Bucharest from intra-hospital infections ( $n=2)$, hospital sewage EF $(n=5)$ and the corresponding WWTP EF $(n=2)$ the WGS demonstrated the presence of OXA-72 and OXA-23 in the IN and the EF of the collecting sewage tank and of genes encoding aminoglycoside modifying enzymes (AMEs) i.e. aph(3')-Vla, ant(3")-Ila, sulphonamides (sul1) and class 1 integrons (qacE $\Delta 1$ ), in all investigated samples (Table 4).

Table 4. ARGs in clinical and wastewater Ab strains isolated in Bucharest in 2018.

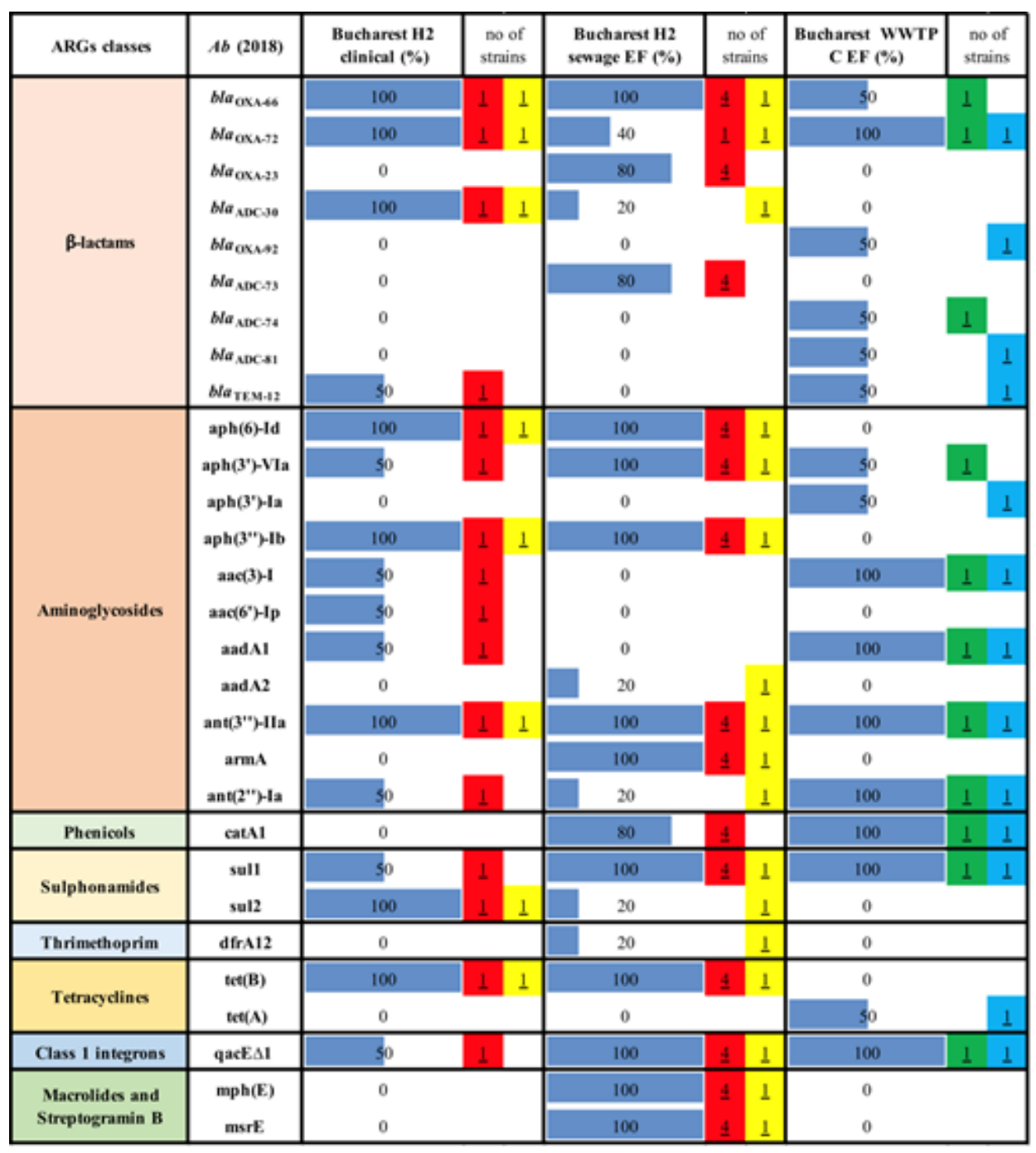

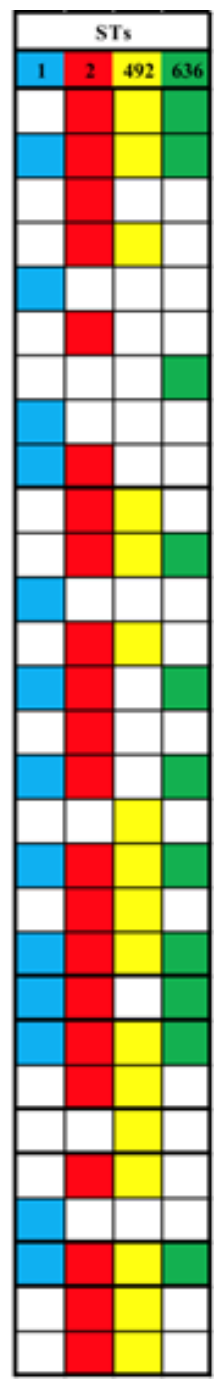

The WGS analysis of $12 \mathrm{Ab}$ clinical strains isolated in 2019 from two hospital units (Bucharest $\mathrm{H} 2$ and Târgoviște), the collecting sewage tank of Bucharest hospital 2 and the sampled corresponding WWTPs from 
Bucharest $(\mathrm{H})$ and Târgoviște $(\mathrm{E})$ revealed the presence of $b / a_{O X A-23}$ in all sampled points from Bucharest. The presence of both $b / a_{\text {OXA-23 }}$ and $b / a_{0 X A-72}$ was shown in clinical $A b$ strains from Târgoviște hospital unit and in the corresponding WWTP (i.e., of $b / a_{0 X A-23}$ in EF and of $b / a_{0 X A-72}$ in the RS) (Supplemental Table 5). Similarly, the AMEs (i.e. aph(6)-Id, ant(3")-Ila), sulphonamides resistance (sul 1) and class 1 integrons (qacE $\Delta 1$ ) were present in all sampled sites from Bucharest. The WGS of nine $A b$ clinical and wastewater strains from Eastern and Northern Romania revealed a high diversity of ARGs, with differences between different cities, i.e.: bla OXA-23, $_{1}$ aph(6)-Id, aph(3")-Ib, armA, sul 1, tet(B), mph(E), msrE and qacE $\Delta$ in Galați WWTP (D) and bla OXA-72, aph(3')-la, aac(3)-I, aadA1, ant(2")-la, sul1 and qacE $\Delta 1$ in lași WWTP (G) (Supplemental Table 5).

Table 5. ARGs in clinical and wastewater $A b$ strains isolated in 2019.

The WGS analysis of the acquired resistome of the 10 Pa strains recovered in 2018 from two Bucharest hospital units and their collecting sewage tanks demonstrated the dissemination of $\mathrm{CP} b / a_{\mathrm{MP}-13}$ and of genes encoding AMEs (aph(3')-llb, ant(2")-la), fosfomycin (fosA), phenicols (catB7, bcr1) and trimethoprim-sulfamethoxazole (sul1) resistance in the case of one Bucharest hospital and its effluent (Table 6). In the case of the second investigated hospital and the corresponding sewage tank, there has been noticed the presence of genes encoding AMEs (aph(3')-llb) and phenicols (catB) (Table 6).

Table 6. ARGs in clinical and wastewater Pa strains isolated in Bucharest in 2018. 


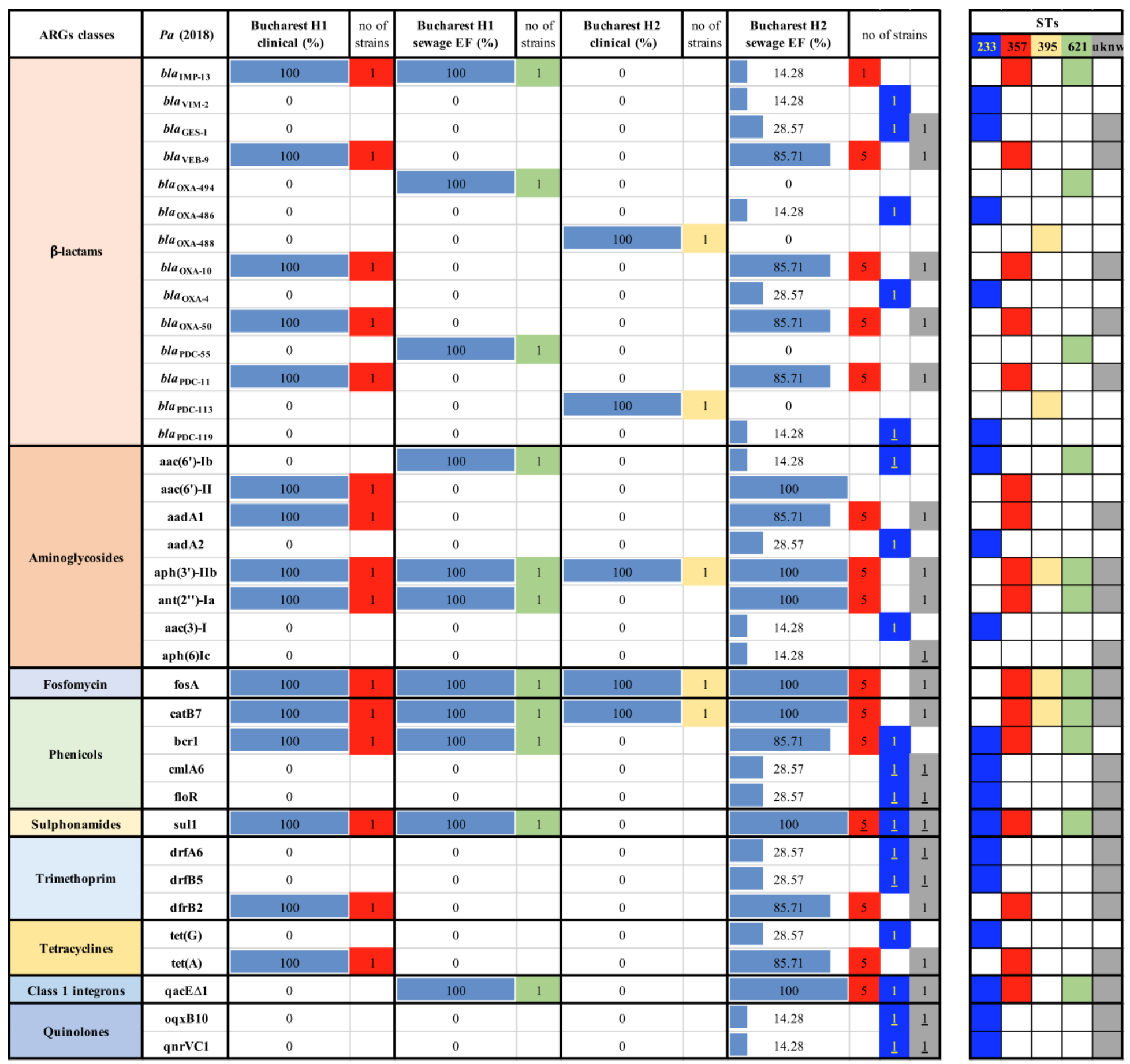

The ARGs distribution in four Pa strains recovered in 2019 from Northern and Eastern Romania revealed the presence of ESBL encoding genes (b/a TEM-40, bla $\left.a_{\text {VEB-9 }}\right)$, AMEs encoding genes (aac(6')-II, aadA1, aph(3')-IIb) as well as determinants of resistance to fosfomycin (fosA), phenicols (catB7, bcr1), tetracycline [tet(A)] and class 1 integrons (qacE $\Delta 1$ ) in clinical and wastewater samples. Regarding the six $P a$ clinical and wastewater strains from Central and Western regions of Romania, the presence of resistance genes encoding for fosfomycin (fosA) and phenicols (catB7, bcr1) has been observed in Pa strains from almost all sources (Table 7).

Table 7. ARGs in clinical and wastewater Pa strains isolated from North - Eastern and Central - Western Romania in 2019. 


\begin{tabular}{|c|c|c|c|c|c|c|c|c|c|c|c|}
\hline ARGs classes & $P a$ (2018) & $\begin{array}{c}\text { Bucharest H1 } \\
\text { clinical (\%) }\end{array}$ & \begin{tabular}{|l|} 
no of \\
strains
\end{tabular} & $\begin{array}{c}\text { Bucharest H1 } \\
\text { sewage EF (\%) }\end{array}$ & \begin{tabular}{|l|} 
no of \\
strains
\end{tabular} & $\begin{array}{c}\text { Bucharest H2 } \\
\text { clinical (\%) }\end{array}$ & $\begin{array}{c}\text { no of } \\
\text { strains }\end{array}$ & $\begin{array}{c}\text { Bucharest H2 } \\
\text { sewage EF (\%) }\end{array}$ & \multicolumn{3}{|c|}{ no of strains } \\
\hline \multirow{14}{*}{$\beta$-lactams } & $b l a_{\mathrm{IMP}-13}$ & 100 & 1 & 100 & 1 & 0 & & 14.28 & 1 & & \\
\hline & $b l a_{\mathrm{VIM}-2}$ & 0 & & 0 & & 0 & & 14.28 & & & \\
\hline & $b l a_{\mathrm{GES}-1}$ & 0 & & 0 & & 0 & & 28.57 & & & 1 \\
\hline & $b l a_{\mathrm{VEB}-9}$ & 100 & 1 & 0 & & 0 & & 85.71 & 5 & & 1 \\
\hline & $b^{\prime} a_{\text {OXA-494 }}$ & 0 & & 100 & 1 & 0 & & 0 & & & \\
\hline & $b^{\prime a} a_{\text {OXA } 486}$ & 0 & & 0 & & 0 & & 14.28 & & & \\
\hline & $b l a_{\text {OXA } 488}$ & 0 & & 0 & & 100 & 1 & 0 & & & \\
\hline & $b_{\text {OXA-10 }}$ & 100 & 1 & 0 & & 0 & & 85.71 & 5 & & 1 \\
\hline & $b l a_{\text {OXA }}$ & 0 & & 0 & & 0 & & 28.57 & & & \\
\hline & $b l a_{\text {OXA-50 }}$ & 100 & 1 & 0 & & 0 & & 85.71 & 5 & & 1 \\
\hline & $b l a_{\mathrm{PDC}-55}$ & 0 & & 100 & 1 & 0 & & 0 & & & \\
\hline & $b l a_{\mathrm{PDC}-11}$ & 100 & 1 & 0 & & 0 & & 85.71 & 5 & & 1 \\
\hline & $b l a_{\mathrm{PDC}-113}$ & 0 & & 0 & & 100 & 1 & 0 & & & \\
\hline & bla $_{\mathrm{PDC}-119}$ & 0 & & 0 & & 0 & & 14.28 & & 1 & \\
\hline \multirow{8}{*}{ Aminoglycosides } & aac(6')-Ib & 0 & & 100 & 1 & 0 & & 14.28 & & & \\
\hline & aac(6')-II & 100 & 1 & 0 & & 0 & & 100 & & & \\
\hline & $\operatorname{aadA1}$ & 100 & 1 & 0 & & 0 & & 85.71 & 5 & & 1 \\
\hline & $\operatorname{aadA2}$ & 0 & & 0 & & 0 & & 28.57 & & & \\
\hline & aph(3')-IIb & 100 & 1 & 100 & 1 & 100 & 1 & 100 & 5 & & 1 \\
\hline & ant(2")-Ia & 100 & 1 & 100 & 1 & 0 & & 100 & 5 & & 1 \\
\hline & $\operatorname{aac}(3)-I$ & 0 & & 0 & & 0 & & 14.28 & & & \\
\hline & $\operatorname{aph}(6) I c$ & 0 & & 0 & & 0 & & 14.28 & & & $\underline{1}$ \\
\hline Fosfomycin & fos A & 100 & 1 & 100 & 1 & 100 & 1 & 100 & 5 & & 1 \\
\hline \multirow{4}{*}{ Phenicols } & catB7 & 100 & 1 & 100 & 1 & 100 & 1 & 100 & 5 & & 1 \\
\hline & ber1 & 100 & 1 & 100 & 1 & 0 & & 85.71 & 5 & & \\
\hline & cmlA6 & 0 & & 0 & & 0 & & 28.57 & & & 1 \\
\hline & floR & 0 & & 0 & & 0 & & 28.57 & & & 1 \\
\hline Sulphonamides & sul1 & 100 & 1 & 100 & 1 & 0 & & 100 & $\underline{5}$ & 1 & 1 \\
\hline \multirow{3}{*}{ Trimethoprim } & drfa6 & 0 & & 0 & & 0 & & 28.57 & & & 1 \\
\hline & drfB5 & 0 & & 0 & & 0 & & 28.57 & & & 1 \\
\hline & dfrB2 & 100 & 1 & 0 & & 0 & & 85.71 & 5 & & 1 \\
\hline \multirow{2}{*}{ Tetracyclines } & $\operatorname{tet}(\mathbf{G})$ & 0 & & 0 & & 0 & & 28.57 & & & \\
\hline & $\operatorname{tet}(\mathrm{A})$ & 100 & 1 & 0 & & 0 & & 85.71 & 5 & & 1 \\
\hline Class 1 integrons & qacE $\Delta 1$ & 0 & & 100 & 1 & 0 & & 100 & 5 & 1 & 1 \\
\hline \multirow{2}{*}{ Quinolones } & oqxB10 & 0 & & 0 & & 0 & & 14.28 & & 1 & 1 \\
\hline & qnrVC1 & 0 & & 0 & & 0 & & 14.28 & & & 1 \\
\hline
\end{tabular}

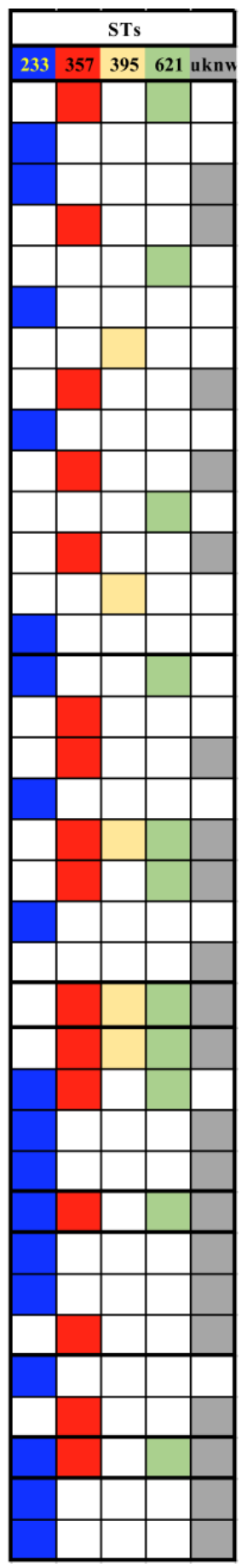

\section{$A b$ and Pa strains molecular phylogeny}

The $A b$ strains phylogeny, MLST profiles and SNP analyses highlight the relatedness between the strains which were divided in six groups.

In group I there were included clinical isolates from lași, Târgoviște and Cluj and in the effluent and downstream of Bucharest WWTP C which belonged to ST636. The SNP analysis suggests the similarities between a clinical isolate sampled in 2019 and the two aquatic strains from this group, sampled in 2018 (harboring 51 and 60 SNPs of the clinical strain); the group II included most of the strains (clinical and wastewater isolates from all investigated regions) belonging to ST2, a successful widespread $A b$ clone. SNP analyses suggest the relatedness between clinical and hospital wastewater strains (189-201+202+203+204, thus less than 20 SNPs 
between clinical and hospital sewage), and more intriguing, the relatedness between strains sampled in clinics and urban WWTPs (169-184 =15 SNPs, 187-1803303 =22 SNPs), suggesting the dissemination of clinical $A b$ ST2 strains in the wastewaters (Table 8); the group III was represented by strains isolated from Bucharest hospital and its collecting sewage tank isolates belonging to ST492, all of them being closely related (26 SNPs); in group IV clinical strains and aquatic strains isolated from Bucharest belonging to ST79 were included; these strains were less related (577 SNPs); the group V included wastewater strains isolated from South Romania belonging to ST1, the isolates being also less related ( $>700$ SNPs); group VI included only environmental strains from the Northern region of the country belonging to ST155 and two related novel STs (Fig. 4).

Table. 8. Matrix representation of calculated SNPs distances between the closely related ST2 strains. 


\begin{tabular}{|c|c|c|c|c|c|c|c|c|c|c|c|c|}
\hline $\begin{array}{l}\text { Strain } \\
\text { code/Isolation } \\
\text { source }\end{array}$ & $\begin{array}{l}187 \\
\text { BL3 } \\
\text { Ab11 }\end{array}$ & $\begin{array}{l}169 \\
\mathrm{DF} 0462 \\
\mathrm{Ab}\end{array}$ & $\begin{array}{l}1803303 \\
\text { WWTP C } \\
\text { DO }\end{array}$ & $\begin{array}{l}182 \\
19001 \\
\mathrm{CNE1} \\
\mathrm{Ab}\end{array}$ & $\begin{array}{l}183 \\
19003 \\
\mathrm{CNE4} \\
\mathrm{Ab}\end{array}$ & $\begin{array}{l}184 \\
19002 \\
\mathrm{CNE} 1 \\
\mathrm{Ab}\end{array}$ & $\begin{array}{l}185 \\
19011 \\
\text { CNE6 } \\
\mathrm{Ab}\end{array}$ & $\begin{array}{l}186 \\
19012 \\
\mathrm{ENE2} \\
\mathrm{Ab}\end{array}$ & $\begin{array}{l}189 \\
\text { BL3 } \\
\text { Ab5 }\end{array}$ & $\begin{array}{l}201 \\
18003 \\
\text { CN10 } \\
\mathrm{Ab}\end{array}$ & $\begin{array}{l}202 \\
18002 \\
\mathrm{CN} 6 \\
\mathrm{Ab}\end{array}$ & $\begin{array}{l}203 \\
18001 \\
\mathrm{CN7} \\
\mathrm{Ab}\end{array}$ \\
\hline $\begin{array}{l}187 \\
\text { BL3Ab11 - } \\
\text { clinical Bals }\end{array}$ & & & & & & & & & & & & \\
\hline $\begin{array}{l}169 \\
\text { DF0462 Ab - } \\
\text { clinical Cluj }\end{array}$ & 110 & & & & & & & & & & & \\
\hline $\begin{array}{l}1803303 \\
\text { WWTP C DO }\end{array}$ & 75 & 140 & & & & & & & & & & \\
\hline $\begin{array}{l}182 \\
19001 \text { CNE1 } \\
\mathrm{Ab}-\text { WWTP D } \\
\text { IN }\end{array}$ & 580 & 140 & 521 & & & & & & & & & \\
\hline $\begin{array}{l}183 \\
19003 \text { CNE4 } \\
\mathrm{Ab}-\text { WWTP D } \\
\text { EF }\end{array}$ & 589 & 91 & 542 & 64 & & & & & & & & \\
\hline $\begin{array}{l}184 \\
19002 \text { CNE1 } \\
\text { Ab - WWTP D } \\
\text { RS }\end{array}$ & 616 & 109 & 555 & 73 & 129 & & & & & & & \\
\hline $\begin{array}{l}185 \\
19011 \text { CNE6 } \\
\text { Ab -Bals } \\
\text { sewage IN }\end{array}$ & 843 & 417 & 798 & 465 & 257 & 463 & & & & & & \\
\hline $\begin{array}{l}186 \\
19012 \text { ENE2 } \\
\text { Ab -Bals } \\
\text { sewage EF } \\
\end{array}$ & 844 & 418 & 800 & 466 & 257 & 463 & 2 & & & & & \\
\hline $\begin{array}{l}189 \\
\text { BL3 Ab5 - } \\
\text { clinical Bals }\end{array}$ & 732 & 273 & 704 & 423 & 348 & 424 & 353 & 337 & & & & \\
\hline $\begin{array}{l}201 \\
18003 \text { CN10 } \\
\text { Ab - Bals } \\
\text { sewage IN }\end{array}$ & 921 & 456 & 895 & 593 & 521 & 588 & 345 & 338 & 35 & & & \\
\hline $\begin{array}{l}202 \\
18002 \text { CN6 Ab } \\
\text { - Bals sewage } \\
\text { IN }\end{array}$ & 915 & 449 & 888 & 523 & 523 & 589 & 344 & 341 & 48 & 6 & & \\
\hline $\begin{array}{l}203 \\
18001 \mathrm{CN7} \mathrm{Ab} \\
\text { - Bals sewage } \\
\text { EF }\end{array}$ & 922 & 458 & 897 & 525 & 525 & 592 & 348 & 335 & 37 & 4 & 4 & \\
\hline $\begin{array}{l}204 \\
18004 \text { CN10 } \\
\text { Ab - Bals } \\
\text { sewage EF }\end{array}$ & 934 & 461 & 907 & 525 & 525 & 593 & 334 & 329 & 33 & 4 & 6 & 6 \\
\hline
\end{tabular}

Conjugation assays revealed a clear dissemination of the same circulating clones from the hospital units into different aquatic compartments [i.e. ST2 encountered in Bucharest hospital unit and the corresponding sampled 
WWTP in 2019 carrying the same CP encoding gene (bla $a_{\text {OXA-23 }}$ or bla $a_{\text {OXA-72 }}$ ) in $A b$ strains; ST2 carrying $b / a_{\text {OXA- }}$ 72 gene in $A b$ strains from Târgoviște hospital unit and $b / a_{\mathrm{OXA}-23}$ in the EF of the corresponding WWTP E].

The Pa strains (Fig. 5) were also grouped in six phylogenetic groups: group I included wastewater isolates from Timișoara, and one clinical strain from the Bucharest hospital that belonged to three singleton STs (ST252, ST254 and ST395); group II comprises clinical strains from Central Romania (Cluj hospital) and one collecting sewage tank from a hospital unit in Bucharest that belonged to the epidemic clone ST233; group III included strains isolated from lași hospital sewage and its collecting WWTP G belonging to ST640; group IV (Bucharest hospital unit collecting sewage tank isolate belonging to ST621); group V (wastewater strains from central Romania that belonged to ST620); group VI contained the majority of the strains (clinical and wastewater isolates from South and East Romania) that belonged to the widespread ST357 and one unknown ST (Fig. 5).

The spread of the same epidemic clone has been noticed, from the hospital unit into the natural aquatic recipient from the East part of the country - Galați hospital unit and the receiving WWTP D (ST357 carrying the blavEB${ }_{9}$ ESBL encoding gene). As revealed by the SNPs analyses, the two ST640 strains (lași hospital and sludge form the lași urban WWTP) represent the same clone (32 SNPs, the proposed threshold being 37 SNPs). The other Pa strains are more diverse, even within the same clone the strains being more distantly related (>100 SNPs); this fact was also suggested by the difference between the core genome (4716 genes) and the pan genome (12395 genes) calculated for all the Pa strains included in this study.

\section{Discussion}

Hospitals are a concentrated source of MDR bacteria, which besides having clinical consequences (treatment options are limited and expensive), can be released in wastewater and finally into the environment [45]. Previous studies have revealed the presence of beta-lactam, tetracyclines, quinolones and sulfonamides resistance genes in both natural and polluted aquatic environments, indicating that these determinants are released from clinical into aquatic environments, and then further disseminated to opportunistic pathogens [46]. Therefore, rapid identification of high-risk clones is essential for segregation of infected patients, preventing the spreading of resistance and improving the antimicrobial treatment. This requires the knowledge of the genetic environment and the carrying platforms of ARGs, as well as the development of new methods for assessing the spreading potential of ARGs mediated by mobile genetic elements in both aquatic and hospital environments.

In Romania, in contrast to clinical studies [47-50, 27, 51-58, 28, 59-61] there is little information available on the epidemiology of AMR reservoirs in the environment, especially in polluted water and rivers. We have previously shown that MDR, CP and ESBL-producing K. pneumoniae isolated from clinics, hospital wastewater and urban WWTPs from different regions of the country exhibit multiple antibiotic and antiseptic resistance, as well as virulence genes, with the ST101 clone being the most frequently encountered in all sampling sites [62]. Also, we have demonstrated the spread of K. pneumoniae ST101 from hospital to wastewater influent and its persistence in the wastewater effluent after the chlorine treatment, suggesting its dissemination in the community and in different aquatic compartments [63]. In our previous research, we have shown that enterococci and Enterobacterales strains in four Romanian natural aquatic fishery lowland salted lakes from Natura 2000 Network are carrying a high diversity of resistance markers correlated with class 1 integrons [64]. Other authors have found tetracycline and sulfonamides ARGs in the WWTP and the receiver river from the northwestern 
Romania and demonstrated that some ARGs, such as bla $a_{\mathrm{VIM}}$ and bla $\mathrm{SHV}_{\mathrm{V}}$ could persist in the chlorinated hospital wastewater being detected both in the influent and chlorinated effluent $[65,66]$.

The purpose of this study was to characterize the AMR profiles and clonality of two of the most dangerous ESKAPE pathogens, $A b$ and $P a$, isolated for two consecutive years from hospital settings, hospital collecting sewage tanks and the receiving WWTPs from three different geographical regions of Romania. The clinical and environmental $A b$ isolates recovered from different geographical regions of Romania revealed high AMR and MDR levels. In another study, from a significant number of groundwater, surface water, and soil samples from Hungary, there were isolated different Acinetobacter species (i.e., A. baumannii, A. johnsonii, A. gyllenbergii and A. beijerinckii, with $8.10 \%$ of $A$. beijerinckii) exhibiting a MDR phenotype [67].

In our study, both imipenem-resistant $A b$ and $P s$ strains were also resistant to other classes of clinically important antibiotics, including quinolones (ciprofloxacin) and aminoglycosides (gentamicin). The phenotypic resistance profiles and MDR rates have largely varied by sampling point and by geographic location. The highest MDR rates in aquatic isolates were recorded in Galați WWTP (D), that could be explained by the location of this county on the lower course of Danube River. The Danube River is considered the most important non-oceanic body of water in Europe and the "future central axis for the European Union", with its Danube Delta being included in the Biosphere Reserve and Ramsar Sites lists. The Danube River crosses ten countries, so this basin represents an optimal pool for resistant pathogens and anthropogenic pollutants dissemination and accumulation throughout large and distant areas, being assigned as a reservoir of AMR. The following two locations with high MDR rates in the aquatic isolates were Bucharest $(\mathrm{H})$ (the capital and largest city) and Târgoviște (E), both located in the Southern part of the country.

The most frequently CPs encountered in clinical and environmental $A b$ strains were OXA-23 and OXA-24, while the ESBLs were represented by SHV, TEM and GES. Hrenoic et al., in 2016 investigated the AMR of $A b$ recovered from the IN and the final EF of a municipal WWTP in Zagreb, Croatia and demonstrated that $66.66 \%$ of the $A b$ isolates were positive for the acquired CP bla OXA-23 $_{23}$ and bla ${ }_{\mathrm{OXA}-24}[68]$. In the case of $P a$ clinical strains, the following CPs and ESBLs have been detected: IMP, VIM, NDM, VEB, GES and TEM.

WGS bioinformatic analysis of $A b$ strains confirmed that the international clone ST2 is broadly spread in our country. Worldwide CP producers are mostly associated with international clone II and OXA-23 [69, 70, 61]. Other clinical and wastewater isolates belonged to ST636, ST1, ST79, ST492 and ST2 and were associated with OXA72. Other research group demonstrated recently that carbapenem resistant $A b$ isolates recovered from different sampling points of a WWTP in Zagreb, positive for bla $a_{0 X A-23}$ belonged to the international clonal lineage IC2, OXA-72 producers to IC1, while the susceptible ones were unclustered [71]. There have also been noticed the presence of two A. baumannii OXA-23 producers belonging to IC2, strains isolated from the sewage of a nursing home in Zagreb [72]. Other authors have demonstrated the association of OXA-23, OXA58, OXA-72 and ST2 in hospital environments from neighboring countries of Romania [73-75]. There has also been pointed out the presence of different $A$. baumannii complex species with MDR phenotypes isolated from environmental samples in one of the Romanian neighbors - Hungary [67].

The WGS analysis of Pa strains has shown that ST357 was associated with IMP-13 in one clinical strain; in the sewage effluent, ST357 was associated with VEB-9 and with both IMP-13 and VEB-9; the epidemic clone ST233 was associated with VIM-2 in clinical and wastewater Pa strains; ST640 with TEM-40 in hospital sewage and 
WWTP; ST621 with IMP-13 in hospital sewage; ST620 with GES-1 in WWTP, while an unknown ST was associated with VIM-2 in a sewage strain. The singletons ST252, 254, 244, 395 were not CP or ESBL producers.

A class 1 integron (qacE $\Delta 1$ ) was present in the majority of the identified $A b$ clones. This association could be the result of co-selection processes due to spread of successful clones (such as ST2, ST636 and ST1 $A b$ ) that were selected by antibiotic treatment in the hospital settings and that were able to accumulate various CPs and ESBLs (i.e. OXA-23, OXA-72, TEM-12, ADC-30, ADC-74, ADC-73, ADC-81). Class 1 integrons were revealed in 80\% of $P a$ strains and $50 \%$ of $P a$ belonging to the epidemic clones ST233, 357 and respectively the ST244.

Since the prevalent clones have a great potential of transmission among patients, the observation that those prevalent clones are significantly associated with the presence of class 1 integrons suggests that those isolates could be a significant reservoir of ARGs and are able to persist in the environment.

\section{Conclusion}

Our study has shown a high prevalence of MDR $A b$ and $P a$ strains in all investigated points (hospital units, their collecting sewage tanks and the sampled WWTPs), highlighted the most frequent CP and ESBL genes, as well as their association with specific sequence types. The reported data highlight the importance of the screening of acquired AMR in the environment and could provide important knowledge for monitoring the ARB and ARGs transmission from hospital into water bodies.

\section{Abbreviations}

AMR: Antimicrobial Resistance

WWTPs: Wastewater Treatment Plants

ARB: Antibiotic Resistant Bacteria

ARGs: Antibiotic Resistance Genes

MDR: Multi-Drug Resistant

CP: Carbapenemase

ESBL: Extended Spectrum Beta-Lactamase

Ab: Acinetobacter baumannii

Pa: Pseudomonas aeruginosa

WGS: Whole-Genome Sequencing

MGEs: Mobile Genetic Elements

HGT: Horizontal Gene Transfer

JPIAMR: Joint Programme Initiative on Antimicrobial Resistance 
CDC: Centers for Disease Control and Prevention

CHDLs: carbapenem-hydrolyzing class $D \beta$-lactamases

MBL: Metallo- $\beta$-Lactamases

VIM: Verona Integron-encoded MBL

IMPs: Imipenemases

NDM: New Delhi Metallo- $\beta$-lactamase

AIM: Australian Imipenemase

CAM: Central Alberta MBL

DIM: Dutch Imipenemase

FIM: Florence Imipenemase

GIM: German Imipenemase

HMB: Hamburg MBL

SPM: São Paulo MBL

SIM: Seoul Imipenemase

VEB: Vietnamese extended-spectrum beta-lactamase

PER: Pseudomonas extended-resistant

TEM: Temoneira patient's name

SHV: Sulfhydryl Variable enzyme

CTX-M: Cefotaxime first isolated in Munich Carbapenemase

GES: Guyana Extended Spectrum $\beta$-lactamase

WWTP C and H: Bucharest WWTP

WWTP E: WWTP Târgoviște

WWTP J: WWTP Râmnicu-Vâlcea

WWTP I: WWTP Cluj

WWTP F: WWTP Timișoara

WWTP G: WWTP Iași 
WWTP D: WWTP Galați

EF: Effluent

IN: Influent

AS: Activated Sludge

RS: Returned Sludge

CLSI: Clinical and Laboratory Standards Institute

RIF: rifampicin

MLST: MultiLocus Sequence Typing

MEM: meropenem

IMP: imipenem

CAZ: ceftazidime

ATM: aztreonam

FEP: cefepime

TZP: piperacillin-tazobactam

CIP: ciprofloxacin

GEN: gentamicin

AK: amikacin

$\mathrm{MH}$ : minocycline

SAM: ampicillin sulbactam

H: Hospital

SNP: Single Nucleotide Polymorphism

\section{Declarations}

Ethics approval and consent to participate

\section{Not applicable}

Consent for publication

Not applicable 
All data analyzed or generated during this study are included in this published article and its Supplementary Information files. Any additional information is available from the corresponding author on reasonable request.

Competing interests

The authors declare that they have no competing interests.

Funding

The financial support of the Research Projects PN-III-P1.1-PD-2016-1798 (PD 148/2018), PN-III-P4-ID-PCCF-20160114 awarded by UEFISCDI and C1.2.PFE-CDI.2021-587 is gratefully acknowledged. The funding had no role in study design, data collection and analysis, decision to publish, or preparation of the manuscript.

Authors' contributions

IG, ICB and MCC designed the study and corrected the manuscript; LM, MP, LIP, ICB, GGP, AB, CS; SG, IL, OS performed the isolation and identification of the samples; IG, AM, CSD, DT, MP, MMM, MIP screened the phenotypic and molecular markers of the isolates; MS, SP performed the WGS experiments; ICB and LIP contributed to the assembling, annotation and characterization of the obtained data; IG and ICB analyzed the WGS and performed the molecular epidemiological studies; MCC, MNL, DO, SP, MS, MP read and corrected the manuscript; IG, ICB and MS have equally contributed to this paper as main authors.

Acknowledgements

Not applicable

\section{References}

1. https://www.ecdc.europa.eu/en/antimicrobial-consumption/database/country-overview. Accessed at December 28, 2021.

2. Baquero F, Martínez JL, Rafael Cantón R. Antibiotics and antibiotic resistance in water environments. Current Opinion in Biotechnology. 2008; 19:260-265.

3. Bergeron S, Boopathy R, Nathaniel R, Corbin A, LaFleur G. Presence of antibiotic resistant bacteria and antibiotic resistance genes in raw source water and treated drinking water. International Biodeterioration \& Biodegradation. 2015; 102:370-374.

4. Meseko C, Makanju O, Ehizibolo D, Muraina I. Veterinary Pharmaceuticals and Antimicrobial Resistance in Developing Countries, Veterinary Medicine and Pharmaceuticals. IntechOpen. 2019. doi: 10.5772/intechopen.84888.

5. Kümmerer K. Antibiotics in the aquatic environment-a review-part I. Chemosphere. 2009; 75(4):417-34.

6. Zhang XX, Zhang T, Fang HH. Antibiotic resistance genes in water environment. Appl Microbiol Biotechnol. 2009; 82(3):397-414.

7. Uluseker C, Kaster KM, Thorsen K, Basiry D, Shobana S, Jain M, et al. A Review on Occurrence and Spread of Antibiotic Resistance in Wastewaters and in Wastewater Treatment Plants: Mechanisms and Perspectives. 
Front. Microbiol. 2021; 12:717-809.

8. Rizzo L, Manaia C, Merlin C, Schwartz T, Dagot C, Ploy MC, Michael I, Fatta-Kassinos D. Urban wastewater treatment plants as hotspots for antibiotic resistant bacteria and genes spread into the environment: a review. Sci Total Environ. 2013; 1(447):345-60.

9. Karkman A, Johnson TA, Lyra C, Stedtfeld RD, Tamminen M, Tiedje JM, Virta M. High-throughput quantification of antibiotic resistance genes from an urban wastewater treatment plant. FEMS Microbiol Ecol. 2016; 92(3):fiw014.

10. Larsson DGJ, Flach CF. Antibiotic resistance in the environment. Nat Rev Microbiol. 2021. doi.org/10.1038/s41579-021-00649-x.

11. Kim S, Aga DS. Potential ecological and human health impacts of antibiotics and antibiotic-resistant bacteria from wastewater treatment plants. J Toxicol Environ Health B Crit Rev. 2007; 10(8):559-73.

12. Alrhmoun M. Hospital wastewaters treatment: upgrading water systems plans and impact on purifying biomass. Environmental Engineering. Université de Limoges. 2014. English ffNNT :2014LIM00042ff. ff.tel01133490.

13. Amarasiri M, Sano D, Suzuki S. Understanding human health risks caused by antibiotic resistant bacteria (ARB) and antibiotic resistance genes (ARG) in water environments: Current knowledge and questions to be answered. Critical Reviews in Environmental Science and Technology. 2020; 50(19): 2016-2059.

14. Krishnasamy S, Vijayan JV, Ramya Srinivasan GD, Indumathi MN. Antibiotic Usage, Residues and Resistance Genes from Food Animals to human and environment: An Indian scenario. Journal of Environmental Chemical Engineering. 2018. doi.org/10.1016/j.jece.2018.02.029.

15. Karkman A, Do TT, Walsh F, Virta MPJ. Antibiotic-Resistance Genes in Waste Water. Trends Microbiol. 2018; 26(3):220-228.

16. https://www.jpiamr.eu/wp-content/uploads/2019/05/JPIAMR_SRIA_final.pdf. Accesses at 28.12.2021.

17. Chokshi A, Sifri Z, Cennimo D, Horng H. Global Contributors to Antibiotic Resistance. J Glob Infect Dis. 2019; 11(1):36-42.

18. De Rosa FG, Corcione S, Pagani N, Di Perri G. 2015. From ESKAPE to ESCAPE, from KPC to CCC. Clin Infect Dis. $2015 ; 60(8):$ 1289-90.

19. Mulani MS, Kamble EE, Kumkar SN, Tawre MS, Pardesi KR. 2019. Emerging Strategies to Combat ESKAPE Pathogens in the Era of Antimicrobial Resistance: A Review. Front Microbiol. 2019; 10:539. doi:10.3389/fmicb.2019.00539.

20. Karlowsky JA, Lob SH, Kazmierczak KM, Hawser SP, Magnet S, Young K, Motyl MR, Sahm DF. In vitro activity of imipenem/relebactam against Gram-negative ESKAPE pathogens isolated in 17 European countries:

2015 SMART surveillance programme. J Antimicrob Chemother. 2018; 73(7):1872-1879.

21. CDC. Antibiotic Resistance Threats in the United States, Atlanta, GA:U.S. Department of Health and Human Services, CDC. 2019. doi.org/10.15620/cdc:82532.

22. Santajit S, Indrawattana N. Mechanisms of Antimicrobial Resistance in ESKAPE Pathogens. Biomed Res Int. 2016; 2475067.

23. Da Silva GJ, Domingues S. Insights on the Horizontal Gene Transfer of Carbapenemase Determinants in the Opportunistic Pathogen Acinetobacter baumannii. Microorganisms. 2016; 29.

doi.org/10.3390/microorganisms4030029.

Page 21/27 
24. Yoon EJ, Jeong SH. Mobile Carbapenemase Genes in Pseudomonas aeruginosa. Front. Microbiol. 2021; 12:614058.

25. Clinical and Laboratory Standards Institute. 2018. Performance standards for antimicrobial susceptibility testing. 28th informational supplement. 2018; M02, M07 and M11.

26. Clinical and Laboratory Standards Institute. 2019. Performance standards for antimicrobial susceptibility testing. 29th informational supplement. 2019; M02, M07 and M11.

27. Gheorghe I, Czobor I, Chifiriuc MC, Borcan E, Ghiță C, Banu O, et al. Molecular screening of carbapenemaseproducing Gram negative strains in Roumanian intensive care units during one year survey. J Med Microbiol. 2014; 63:1303-1310.

28. Gheorghe I, Cristea VC, Marutescu L, Popa M, Murariu C, Trusca BS, Borcan E, Ghiță MC, Lazăr V, Chifiriuc MC. Resistance and virulence features in carbapenem-resistant Acinetobacter baumannii community acquired and nosocomial isolates in Romania. Revista de Chimie. 2019; 10:3502-3507.

29. Feng Y, Yang P, Wang X, Zong Z. Characterization of Acinetobacter johnsonii isolate XBB1 carrying nine plasmids and encoding NDM-1, OXA-58 and PER-1 by genome sequencing. J. Antimicrob. Chemother. 2016; 71, 71-75.

30. Andrews S. FastQC: A Quality Control Tool for High Throughput Sequence Data [Online]. 2010. Available online at: http://www.bioinformatics.babraham.ac.uk/projects/fastqc/

31.Seemann T. Shovill: faster SPAdes assembly of Illumina reads (v1.1.0). 2018;

https://github.com/tseemann/shovill. Accessed 12.06.2020.

32. Seemann T. Prokka: rapid prokaryotic genome annotation. Bioinformatics, 2014; 15;30(14):2068-9.

33. https://github.com/tseemann/abricate. Accessed June 30, 2020.

34. Zankari E, Hasman H, Cosentino S, Vestergaard M, Rasmussen S, Lund O, et al. Identification of acquired antimicrobial resistance genes. J Antimicrob Chemother. 2012; 67(11):2640-4.

35. Cosentino S, Larsen MV, Aarestrup FM, Lund O, 2013. PathogenFinder - Distinguishing Friend from Foe Using Bacterial Whole Genome Sequence Data. PLoS ONE. 2013; 8(10):e77302.

36. Carattoli A, Zankari E, García-Fernández A, Voldby Larsen M, Lund O, Villa L, et al. PlasmidFinder and pMLST: in silico detection and typing of plasmids., Antimicrob. Agents Chemother. 2014; 58(7):3895-903.

37. Feldgarden M, Brover V, Haft DH, Prasad AB, Slotta DJ, Tolstoy I, et al. Validating the AMRFinder Tool and Resistance Gene Database by Using Antimicrobial Resistance Genotype-Phenotype Correlations in a Collection of Isolates. Antimicrobial agents and chemotherapy.2019; 63(11): e00483-19.

38. http://www.genomicepidemiology.org/. Accessed July 20, 2020

39. https://card.mcmaster.ca/. Accessed July 20, 2020.

40. Seemann T, mlst (v2.19.0). Github https://github.com/tseemann/mlst. Accessed July 12,2020.

41. Seemann T. Snippy: fast bacterial variant calling from NGS reads (v4.6.0). https://github.com/tseemann/snippy. 2015, Accessed July 12, 2020.

42. Page AJ, Cummins CA, Hunt M, Wong VK, Reuter S, Holden MT, et al. Roary: Rapid large-scale prokaryote pan genome analysis. Bioinformatics. 2015; 31(22):3691-3.

43. Stamatakis A. RAxML version 8: a tool for phylogenetic analysis and post-analysis of large phylogenies. Bioinformatics. 2014; 30(9):1312-1313. 
44. Letunic I, Bork P. Interactive Tree Of Life (iTOL) v4: recent updates and new development., Nucleic Acids Res. 2019; 47(W1):W256-W259.

45. Magiorakos AP, Srinivasan A, Carey RB, Carmeli Y, Falagas ME, Giske CG. Multidrug-resistant, extensively drug-resistant and pandrug-resistant bacteria: an international expert proposal for interim standard definitions for acquired resistance. Clin Microbiol Infect. 2012; 18(3):268-281.

46. Marinescu F, Marutescu L, Savin I, Lazar V. Antibiotic resistance markers among Gram-negative isolates from wastewater and receiving rivers in South Romania. Romanian Biotechnological Letters. 2015; 20(1):10055-10069.

47. Mereuţă Al, Docquier JD, Rossolini GM, Buiuc D. Detection of metallo-beta-lactamases in Gram-negative bacilli isolated in hospitals from Romania-research fellowship report. Bacteriol Virusol Parazitol Epidemiol. 2007; 52(1-2):45-9.

48. Radu-Popescu MA, Dumitriu S, Enache-Soare S, Bancescu G, Udristoiu A, Cojocaru M, Vagu C. Phenotypic and genotypic characterization of antibiotic resistance patterns in Acinetobacter baumannii strains isolated in a Romanian hospital. Farmacia. 2010; 3:362-367.

49. Bonnin RA, Poirel L, Licker M, Nordmann P. Genetic diversity of carbapenem-hydrolysing $\beta$-lactamases in Acinetobacter baumannii from Romanian hospitals. Clin Microbiol Infect. 2011; 17(10):1524-8.

50. Hurezeanu, D.D., Dragonu, L., Canciovici, C, Ristea D, Ene D, Cotulbea M, et al. Infections with Pseudomonas aeruginosa in patients admitted to the "Victor Babeş" Clinical Hospital of Infectious Diseases and Pneumology, Craiova. BMC Infect Dis. 2013; 13, P40.

51. Gheorghe I, Novais A, Grosso F, Rodrigues C, Chifiriuc MC, Lazar V, Peixe L. Snapshot of carbapenemaseproducing Pseudomonas aeruginosa and Acinetobacter baumannii in Bucharest hospitals reveals unusual clones and novel genetic surroundings for blaOXA-23. J AntimicrobChemother. 2015; 70 (4):1016-1020.

52. Dortet L, Flonta M, Boudehen YM, Creton E, Bernabeu S, Vogel A, Naas T. Dissemination of carbapenemaseproducing Enterobacteriaceae and Pseudomonas aeruginosa in Romania. Antimicrob Agents Chemother. 2015a; 59(11):7100-7103.

53. Timofte D, Panzaru CV, Maciuca IE. Active surveillance scheme in three Romanian hospitals reveals a high prevalence and variety of carbapenamaseproducing Gram-negative bacteria: A pilot study, December 2014 to May 2015. Eurosurveillance. 2016; 21(25):pii=30262.

54. Lăzureanu V, Poroșnicu M, Gândac C, Moisil T, Bădițoiu L, Laza R, et al. Infection with Acinetobacter baumannii in an intensive care unit in the Western part of Romania. BMC Infect Dis. 2016; 16 Suppl 1(Suppl 1):95.

55. Gavriliu LC, Popescu GA, Popescu C. Antimicrobial resistance of Pseudomonas aeruginosa in a Romanian hospital at the dawn of multidrug resistance. Braz J Infect dis. 2016; 20(5):509-510.

56. Călina D, Docea AO, Rosu L, Zlatian O, Rosu AF, Anghelina F et al. Antimicrobial resistance development following surgical site infections. Mol Med Rep. 2017; 15: 681-688.

57. Vata A, Pruna R, Rosu F, Miftode E, Nastase EV, Vata LG, Dorneanu O. Pseudomonas aeruginosa infections in the "Sfânta Parascheva" infectious diseases hospital of lași city. Ro J Infect Dis. 2018; 21(3).

58. Muntean D, Horhat FG, Bădițoiu L, Dumitrașcu V, Bagiu IC, Horhat DI, et al. Multidrug-Resistant GramNegative Bacilli: A Retrospective Study of Trends in a Tertiary Healthcare Unit. Medicina. 2018; 54:92. 
59. Arbune M, Gurau G, Niculet E, lancu AV, Lupasteanu G, Fotea S, et al. Prevalence of Antibiotic Resistance of ESKAPE Pathogens Over Five Years in an Infectious Diseases Hospital from South-East of Romania. Infect Drug Resist. 2021; 14:2369-2378.

60. Buzilă ER, Năstase EV, Luncă C, Bădescu A, Miftode E, lancu LS. Antibiotic resistance of non-fermenting Gram-negative bacilli isolated at a large Infectious Diseases Hospital in North-Eastern Romania, during an 11-year period. Germs. 2021; 11(3):354-362.

61. Gheorghe I, Barbu IC, Surleac M, Sârbu I, Popa LI, Paraschiv S, et al. 2021. Subtypes, resistance and virulence platforms in extended-drug resistant Acinetobacter baumannii Romanian isolates. Sci Rep. 2021; 11:13288.

62. Surleac M, Czobor Barbu I, Paraschiv S, Popa LI, Gheorghe I, Marutescu L, et al. Whole genome sequencing snapshot of multi-drug resistant Klebsiella pneumoniae strains from hospitals and receiving wastewater treatment plants in Southern Romania. PloS ONE. 2020; 15(1): e0228079.

63. Popa LI, Gheorghe I, Barbu IC, Surleac M, Paraschiv S, Măruţescu L, et al. 2021. Multidrug resistant Klebsiella pneumoniae ST101 clone survival chain from inpatients to hospital effluent after chlorine treatment. Front Microbiol. 2021; 11;11:610296.

64. Lazăr V, Gheorghe I, Curutiu C, Savin I, Marinescu F, Cristea VC, et al. 2021. Antibiotic resistance profiles in cultivable microbiota isolated from some romanian natural fishery lakes included in Natura 2000 network. BMC VetRes. 2021; 17(1):52.

65. Țugui CG, et al. Studia Universitatis Babeş-Bolyai Biologia, 2015; LX, Sp. Iss., 33-38.

66. Lupan I, Carpa R, Oltean A, Kelemen BS, Popescu O. Release of Antibiotic Resistant Bacteria by a Waste Treatment Plant from Romania. Microbes Environ. 2017; 32(3):219-225.

67. Radó J, Kaszab E, Benedek T, Kriszt B, Szoboszlay S. First isolation of carbapenem-resistant Acinetobacter beijerinckii from an environmental sample. Acta Microbiologica et Immunologica Hungarica. 2019; 66(1):113-130,

68. Hrenovic J, Goic-Barisic I, Kazazic S, Kovacic A, Ganjto M, Tonkic M. 2016. Carbapenem-resistant isolates of Acinetobacter baumannii in a municipal wastewater treatment plant, Croatia, 2014. Eurosurveillance. 2016; 21(15).

69. Mugnier PD, Poirel L, Naas T, Nordmann P. Worldwide dissemination of the blaOXA-23 carbapenemase gene of Acinetobacter baumannii. Emerg Infect Dis. 2010; (16):35-40.

70. Dortet L, Bonnin RA, Girlich D, Imanci D, Bernabeu S, Fortineau N, Naas T. Whole-Genome Sequence of a European Clone II and OXA-72-producing Acinetobacter baumannii strain from Serbia. Genome Announcements genomea.asm.org. 2015b; 3(6):e01390-15.

71. Higgins PG, Hrenovic J, Seifert H, Dekic S. 2018. Characterization of Acinetobacter baumannii from water and sludge line of secondary wastewater treatment plant. Water Res. 2018; 140:261-267.

72. Bedenic B, Beader N, Siroglavic M, Slade M, Car H, Dekic S, et al. Acinetobacter baumannii from a sewage of a nursing home in Croatia. 28th ECCMID Madrid, Spain, 2018; 21-24 april, E0143.

73. Mammina C, Palma DM, Bonura C, Aleo A, Fasciana T, Sodano C, et al. Epidemiology and clonality of carbapenem-resistant Acinetobacter baumannii from an intensive care unit in Palermo, Italy. BMC Research Notes. 2012; (5):365. 
74. Izdebski R, Janusz Fiett J, Waleria Hryniewicz W, Marek Gniadkowski M. Molecular Analysis of Acinetobacter baumannii Isolates from Invasive Infections in 2009 in Poland. J Clin Microbiol. 2012; 50(11):3813-3815.

75. Petrova AP, Stanimirova ID, Ivanov IN, Petrov MM, Miteva-Katrandzhieva TM, Grivnev VI. Carbapenemase Production of Clinical Isolates Acinetobacter baumannii and Pseudomonas aeruginosa from a Bulgarian University Hospital. Folia Medica. 2017; 59(4): 413-422.

\section{Figures}

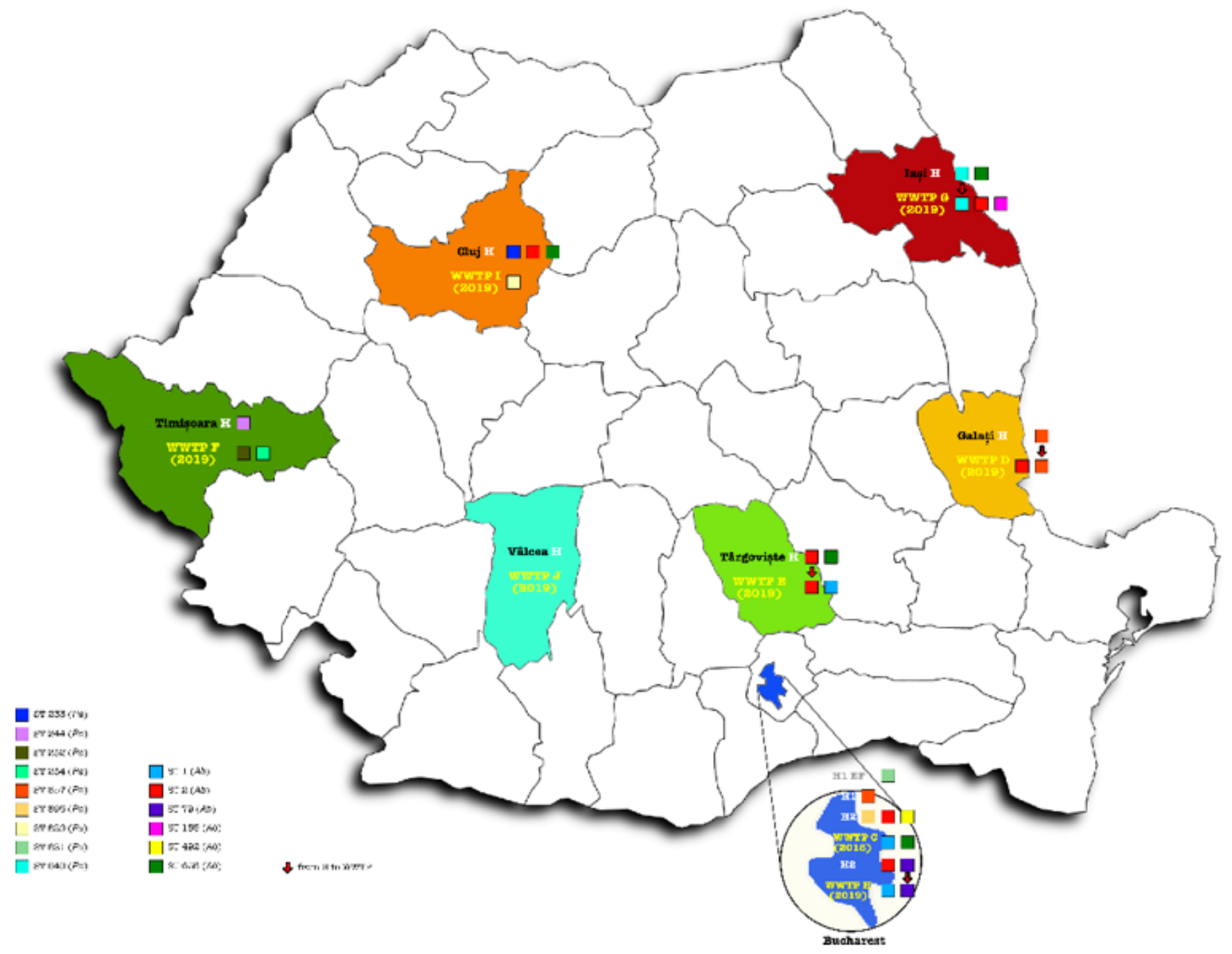

Figure 1

Geographic distribution of the sampling points. 


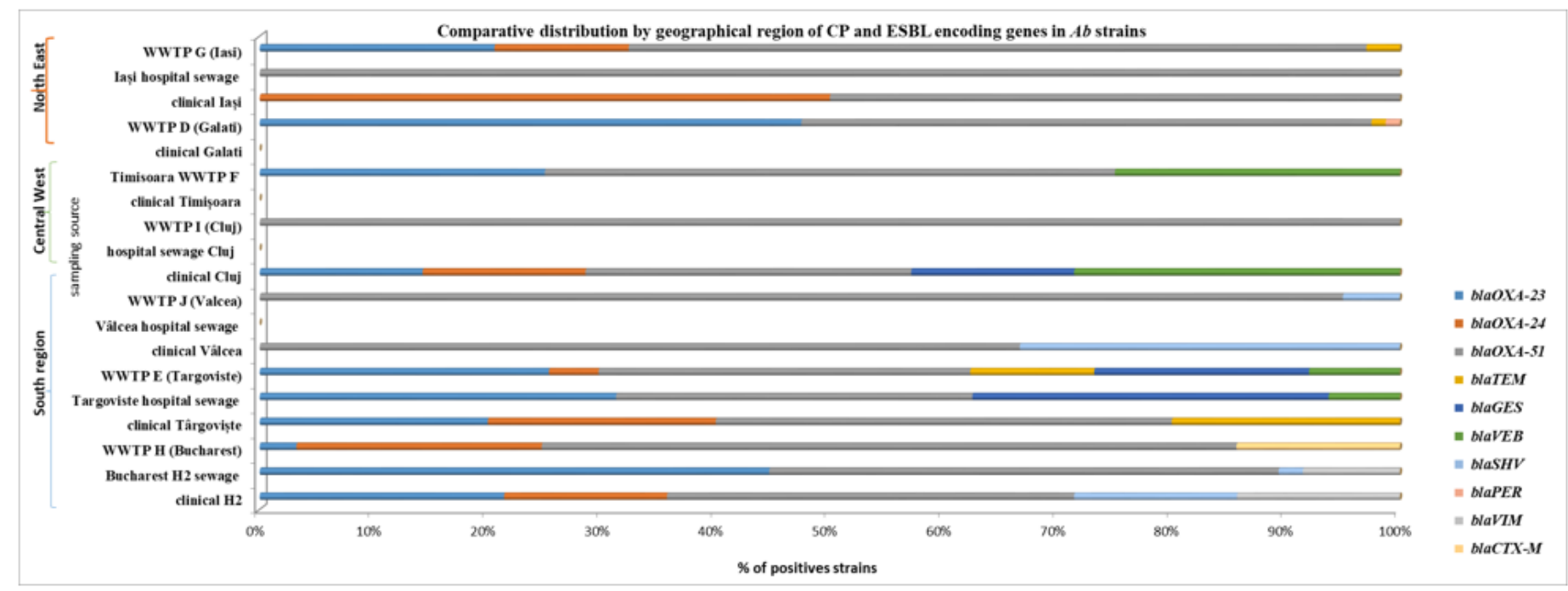

Figure 2

$\mathrm{CP}$ and ESBL encoding genes in clinical and wastewater $A b$ from different geographical regions.

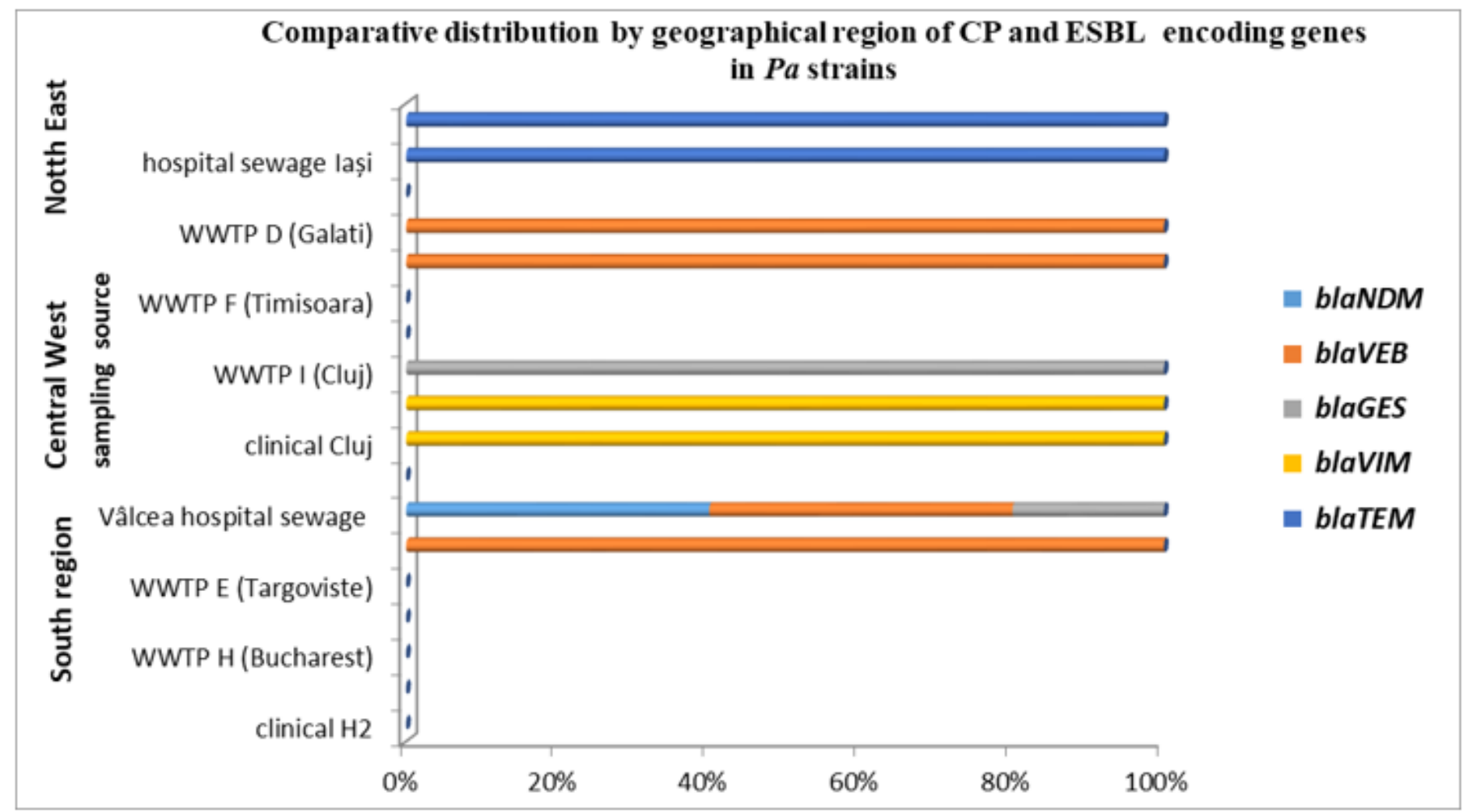

Figure 3

$\mathrm{CP}$ and ESBL encoding genes in clinical and wastewater Pa from different geographical regions. 


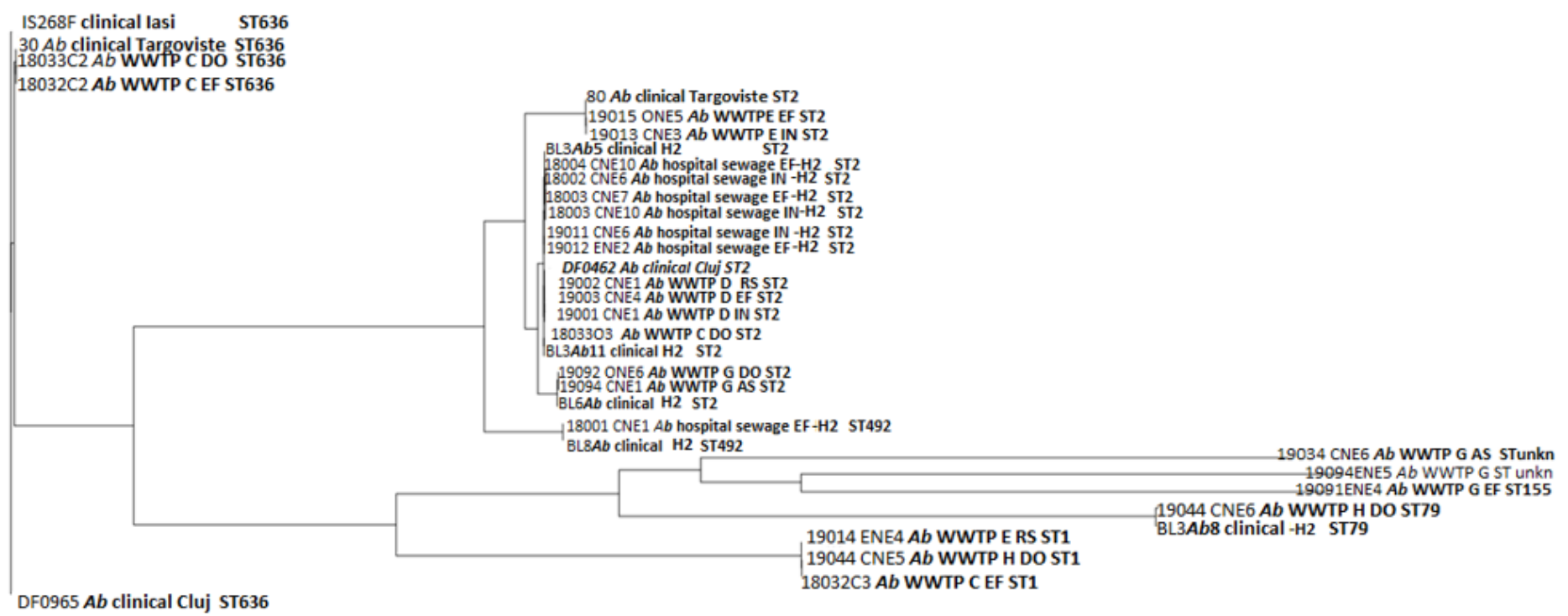

\section{Figure 4}

Phylogenetic tree of clinical and wastewater $A b$ strains.

Figure 5

Phylogenetic tree of clinical and wastewater Pa strains.

\section{Supplementary Files}

This is a list of supplementary files associated with this preprint. Click to download.

- SupplementalTables2and3.tiff

- SupplementalTable5.tiff 